\title{
Benefical effects of mediterranean diet in neuroinflammation and related diseases
}

\author{
Walter Milano ${ }^{1}$, Vincenzo Pizza ${ }^{2}$ and Anna Capasso ${ }^{3 *}$ \\ ${ }^{1}$ Mental Health Unit District 24 ASL Napoli 1 Center, Italy \\ ${ }^{2}$ Neurophysiopathology Service, S. Luca Hospital, Vallo della Lucania (SA), Italy \\ ${ }^{3}$ Department of Pharmacy, University of Salerno, Italy
}

\begin{abstract}
The increase in the average lifespan and the consequent proportional growth of the elderly segment of society has furthered the interest in studying ageing processes.

Ageing may be considered a multifactorial process derived from the interaction between genetic and environmental factors including lifestyle. There is ample evidence in many species that the maximum age attainable (maximum lifespan potential, MLSP) is genetically determined and several mitochondrial DNA polymorphisms are associated with longevity.

Many studies have shown that most of the phenotypic characteristics observed in the aging process are the result of the occurrence, with age, of a low grade chronic pro-inflammatory status called "inflammaging", partially under genetic control. The term indicate that aging is accompanied by a low degree of chronic inflammatory, an up-regulation of inflammatory response and that inflammatory changes are common to many age-related diseases. Therefore, the theory of oxidation-inflammation was proposed as the main cause of aging. Accordingly, the chronic oxidative stress that appears with age affects all cells and especially those of the regulatory systems, such as the nervous, endocrine, and immune systems and the communication between them. This prevents an adequate homeostasis and, therefore, the preservation of health. It was also proposed that the immune system plays a key role in the aging process, specifically in the rate of aging, since there is a relationship between the redox state and functional capacity of immune cells and longevity of individuals. Moreover, the role of the immune system in senescence could be of universal application. A confirmation of the central role of the immune system in oxi-inflamm-aging is that the administration of adequate amounts of antioxidants in the diet improves immune function, decreases their oxidative stress, and consequently increases longevity.
\end{abstract}

The present review was aimed to understand the molecular mechanisms underlying beneficial effects of mediterranean diet on neuroinflammation and related diseases.

\section{Introduction}

In industrialised societies the average lifespan considerably lengthened during the past century, so that whereas in the early twentieth century life expectancy at birth was about 40 to 50 years, today it is almost twice as much and by 2050 it is expected to rise by another 10 years. Italy in particular turns out to be among the most elderly countries in the world thanks to, undoubtedly, improvements in nutrition, sanitation, and medical care. This increase in the average lifespan and the consequent proportional growth of the elderly segment of society has furthered the interest in studying ageing processes [1,2].

Ageing may be considered a multifactorial process derived from the interaction between genetic and environmental factors, and lifestyle. Old age in human beings is characterised by the onset of several diseases which, although not unique to old age, are nonetheless rather strictly correlated to it, the physiological decline over time being a pivotal factor in the increase of the risk the elderly has of developing said diseases.

Over time, many studies have targeted the identification of biological events to which the progressive deterioration over time could be attributed. The view of ageing as a complex multifactorial process has superseded previous monofactorial theories which attributed the phenomenon of ageing to one single cause [3]. In fact, some of the phenomena which characterise physiological ageing can be explained by individual theories, but no one single theory is able to account for the ageing process in its entirety [4-44].

\section{Inflammaging}

The term inflammaging was coined by Claudio Franceschi [45] to indicate that ageing is accompanied by a low degree of chronic inflammation and an up-regulation of the inflammatory response, and that inflammatory changes are common to many age-related diseases [46-63]. Multiple persistent weak stimuli (endogenous and exogenous toxins) cause a prolonged commitment of body's adaptive systems with multiple low-grade inflammatory responses, which tend to become chronic and often asymptomatic. Indeed, patients report vague and nonspecific signs and systemic order symptoms with complex diagnostic definition. Inflammaging is characterized by five conditions: low-grade, controlled, asymptomatic, chronic and systemic inflammation [64]. So inflammaging is the up-regulation of a variety of stress responses at the cellular and molecular levels. Inflammaging is the result of the body's ability to adapt to and counter the effects of a variety of stress factors that cause the accumulation of molecular and cellular damage.

Correspondence to: Anna Capasso, Department of Pharmacy, University of Salerno, Salerno, Italy, E-mail: annacap@unisa.it

Received: December 04, 2017; Accepted: December 29, 2017; Published: January 04, 2018 


\section{Physiopathogenesis}

The relationship between chronic systemic inflammation and ageing is now widely accepted. Many studies have shown that most of the phenotypic characteristics observed in the ageing process are the result of the occurrence, with age, of a low grade chronic proinflammatory state, called "inflammaging", partially under genetic control. This state seems be the result of continuous antigenic stimulation that continues beyond the reproductive age and therefore widely not expected by the evolution $[52,65,66]$. The resulting tissue damage appears to be related to death risk in elderly people and also appears to be deleterious to longevity [67]. Some studies have identified genetic, cellular, and serological markers of inflammaging, such as an immunophenotype characterised by a decrease of naive $\mathrm{T}$ cells and an accumulation of memory cells, increased levels of proinflammatory cytokines, and significant alterations in the frequency of functional of pro- or anti-inflammatory polymorphisms $[54,68,69]$. The inflammaging is characterised by the activation of macrophages and the expansion of specific $\mathrm{T}$ cells clones (megacloni) directed to common virus antigens such as the Cytomegalovirus (CMV) and the Epstein-Barr virus (EBV) [70-74]. In order to clarify the roles of CMV disease 121 subjects have been recently studied. The subjects were between 25 and 100 years old: 18 subjects were serum negative and 103 serum positive for CMV infection [75]. It was also observed that the age-related reduction of $\mathrm{CD} 8+$ naive $\mathrm{T}$ cells was accelerated in $\mathrm{CMV}+$ subjects. The reduction of naive CD8+ cells was accompanied by a progressive increase in CD8+ effectors T cells, CD28-, in CMV+ subjects. Therefore, the CMV seropositivity seems to be associated with many phenotypic and functional alterations of $\mathrm{T}$ cell immunity considered biomarkers of ageing [75]. Another chronic infection that could play a key role in the immune-inflammatory response in the elderly is caused by Herpes Simplex Virus (HSV) that appears to play a role as cofactor in damages involved in Alzheimer's disease [76,77]. A recent prospective study has shown an increased risk of $\mathrm{AD}$ in patients seropositive for IgM-HSV, probably responsible for progressive chronic damage [78]. Inflammaging is a complex inflammatory response to various endogenous and environmental stimuli due mainly to the increase in circulating levels of pro-inflammatory cytokines. Cytokines are a class of soluble proteins responsible for the communication between the different components of the immune system. Cytokines play an important role in inflammation by acting on the targeting, regulation, and termination of inflammatory processes. It has been determined that these molecules also play a central role in the ageing processes. During ageing there is a decrease, reversible, in the levels of IL2 cytokine, which is important in the development of Th1 and population in increased production of pro inflammatory mediators such as IL1, IL6, and TNFalpha [40]. The increase in the age-related inflammatory markers (inflammaging) could be the basis of the reduced ability for elderly subjects to cope with various stressors. The inflammaging process may also generate reactive oxygen species (ROS) that cause oxidative damage and elicit an increase in the release of cytokines, perpetuating a vicious circle resulting in a chronic proinflammatory state where tissue damage and repair mechanisms proceed simultaneously. In this case the damage accumulates slowly and asymptomatically over the years, resulting in ageing and in the development of age-related diseases [59-64]. Reactive oxygen species (ROS) are also capable of inducing profound effects on gene expression and are implicated in the pathogenesis of many age-related diseases such as atherosclerosis, type II diabetes, neurodegeneration, osteoporosis and osteoarthritis, all pathologies which share a strong inflammatory/immunological component. Moreover, oxidative stress and ROS are active inducers of apoptosis and may act as mediators influencing other transcription factors such as NF-kB and AP-1 [68]. Alterations in apoptosis due to ageing may therefore explain some of the most important aspects of immunosenescence [79], such as the accumulation of memory cells, expanded megaclones, the restriction of the repertoire of $\mathrm{T}$ lymphocytes, and the increase in the incidence of autoimmune phenomena. The cellular and molecular mechanisms related to the body's ability to appropriately respond to a series of oxidative stresses and inflammations appear to play an important role in promoting human longevity and in avoiding/delaying the major age-related diseases. The participation of inflammatory cells and molecules in the pathogenesis of many age-related diseases such as atherosclerosis, Alzheimer, and Parkinson's disease is well documented. Conversely the control of inflammations may allow successful ageing that can be better achieved as is evident in centenarians. They are the living example of successful ageing, the desirable type of ageing, free from chronic debilitating diseases, and which preserves physical selfsufficiency and mental health. These subjects are a highly selected group who have lived for over a hundred years without the onset of any major age-related diseases; the study of these subjects could detect the biological basis of ageing or the combination of genes and lifestyle that have allowed these people to avoid the aforementioned age-associated diseases. The "INCHIANTI Study", concluded in 2004 [80], showed that elderly subjects have high levels of IL-6, CRP, and IL-1 compared to young subjects in good health. A further study on a group of Italian centenarians showed that subjects genetically predisposed to produce IL- 6 in old age have a reduced ability to reach the outer limits of human life.

Another study by Lyons et al. [62] on a group of centenarians assessed the levels of two cytokines, the anti-inflammatory protein IL-10 and the TNF-alpha, a protein that promotes inflammation. The study showed that centenarians express genes encoding high levels of IL-10 and low levels of TNF-alpha compared to the control group of younger subjects. Studies on the elderly and centenarians have shown that the frequency of variants (polymorphisms) of key genes involved in immune response and low-grade inflammation are present with different frequencies in centenarians by comparison to the young $[74,81,82]$. The presence of an anti-inflammatory genotype in centenarians suggests that chronic inflammation is a key predictive marker of mortality and morbidity in senescence. Signs of inflammaging have also been found unexpectedly in healthy centenarians, together with an increase of inflammatory markers, such as IL10 and TGF-beta $[83,84]$. It seems that beside the existent inflammatory phenomena, anti-inflammatory phenomena (antiflammaging) are also present and are equally important for longevity, and that longevity is the result of balancing these two conflicting responses [85]. A long life, which exceeds 90 years of age seems to have a strong genetic basis, which explains why the almost-one-hundred-years-old and centenarians are grouped into families. Longevity seems to be greatly influenced by a complex genetic pattern and not by a few isolated genes. It is easy to assume that genes and genetic variants associated with strong immune responses and inflammation have been selected and this has helped to ensure survival in reproductive age.

It has been proposed that an effective inflammatory response useful for the resolution of infection in young age may become the cause of much pathology such as arthritis, diabetes, cardiovascular and neurodegenerative diseases in old age. The double biological role of inflammation, positive when young and negative when older, is consistent with the antagonistic pleiotropy theory that a gene can have opposite effects at different periods of life. Inflammation itself is not a negative phenomenon; indeed, in response to various stimuli, the 
immune system implements a complex series of local and systemic reactions that prevent tissue damage, isolate and destroy any infectious agents and activate the repair process. The damage is related to the increase in life expectancy not anticipated by evolution. When life expectancy is prolonged it means that immune system continues to react against external agents for decades longer than expected. The increased antigenic load eventually establishes a chronic inflammation that contributes to the deterioration of various organs, becoming a risk factor for all typical chronic diseases of old age. Indeed, the elderly that have higher blood levels of an acute phase protein, the PCR, are subject to chronic inflammatory diseases.

The systemic consequences determine a pattern of changes that goes by the name of "fragility" (chronic inflammatory disease or frailty) and epidemiological studies suggest that low grade inflammation observed in the ageing process promotes an atherogenic profile that is related to other chronic inflammatory diseases typical of old age. Other genetic and environmental factors that promote the diseases keep all their importance and even determinate what will be the principal organ affected; the differences in the inflammatory status help to explain why not all the subjects develop age-related disease, even under the same risk factors. The permanent exposure to a variety of infectious agents for a long period (chronic antigenic load) influences the ageing of the immune system (Immunosenescence) $[58,86]$.

So the potential of our immune system, genetically determined, is gradually depleted over time, in relation with the pathogenic antigen aggression. The improved hygienic conditions typical of industrialized countries may have reduced significantly the antigenic overload, preserving longer the immune system and avoiding a rapid depletion. This factor, in addition to reduced mortality due to acute infectious diseases, may have contributed to an increased life expectancy and to the increase in the number of subjects who reach the extreme limit of life.

\section{Related disorders}

Inflammation is a chronic systemic cause of many age-related diseases such as atherosclerosis and cardiovascular illness, Alzheimer's disease and cancer.

Recent research has shown that chronic systemic inflammation contributes to anxiety, depression, cognitive decline, insulin resistance and adult-onset diabetes, obesity, and Parkinson's disease.

\section{Cancer}

Cancer is a disease that occurs mostly in elderly subjects. The average age for diagnosis in industrialized countries is approaching 70 years of age and it is expected to increase [87]. This may be due to various reasons such as increased duration of exposure to carcinogenic factors, stronger cell susceptibility to environmental carcinogens $[88,89]$ or to the immunosenescence in elderly [90]. Over the past 15 years a strong link between chronic inflammations, induced by chemical, biological, mechanical or physical lesions, and cancer has been discovered. For example, bowel inflammatory disease, ulcerative colitis and Crohn's disease are clinical conditions predisposing to the development of large intestine or terminal ileum cancer [91,92]. Helicobacter pylori is a microorganism associated with atrophic gastritis, mucosal dysplasia, gastric adenocarcinoma. Inflammation plays an important role in the development of solid tumours such as colon cancer. This was clearly demonstrated by a prospective case-control study of 22887 adults followed for 11 years, where 172 cases of colon cancer were identified. In these patients plasma concentrations of CRP were higher compared to control cases [93]. Cancer susceptibility and severity may be associated with functional polymorphisms of cytokine genes involved in regulating inflammation. In particular, polymorphisms affecting IL6 and IL10 genes may influence susceptibility and in some cases the prognosis of cancer. Many different mechanisms may also link inflammation to cancer:

1. Induction of angiogenesis by inflammatory factors promotes cancer progression [94].

2. Increased release of pro inflammatory factors and certain cytokines such as IL1, TNF alpha and interferon are both involved in inflammation and cancer development $[94,95]$.

3. Free radicals production promotes carcinogenesis [94].

Inflammatory state is the crucial mediator of the intermediate stages of tumour development. In cancer, genetic damage is the fuse that triggers the fire and inflammation is the fuel that feeds it. In 1978 Alberto Mantovani observed that innate immunity cells tend to cluster around some tumours [96]. Then Pollard et al. showed that cancer cells "reeducate" macrophages, turning them into cytokines and growth factors factories that stimulate cancer growth by acting as tumour promoters [96]. Macrophages produce tumour necrosis factor (NFK), which activates the nuclear factor NFkB in cancer cells. This nuclear factor triggers the production of proteins that stop apoptosis and activate cell proliferation. So, the precancerous tissue in chronic inflammatory cells uses the innate immune system to help the tumour grow. How this process starts remains unanswered for the time being [96].

\section{Atherosclerosis}

Almost the $50 \%$ of all deaths in the developed world and $25 \%$ of the deaths in developing countries are attributable to cardiovascular diseases. Atherosclerosis is the leading cause of heart disease and stroke. Atherosclerosis, considered in the past a disease of lipid accumulation, is now considered a chronic inflammatory disease of large and medium size vessels [97]. The lesions begin in childhood as lipid streaks (reversible), which in old age tend to become plaques proper that can narrow the arterial lumen or ulcer and complicate in thrombosis which can occlude the lumen. The clinical manifestations depend on the vessels involved, so it will be angina pectoris and heart attack during when the coronary arteries are involved, stroke if the arteries of the central nervous system are involved, and peripheral arterial disease if the peripheral circulation is concerned. It is clear that the seats that are more predisposed to the development of atherosclerotic lesions are the ramifications and the curvatures of the vessels of the blood stream due to friction on its surface (hemodynamic stress), an important factor for the intima thickening. The early lesion of atherosclerosis is identified in the functional/dysfunctional endothelial alteration by cardiovascular risk factors (smoking, hypercholesterolemia, hyperhomocysteinemia, hypertension, obesity and diabetes mellitus, and possibly infectious and immunological causes) and to the accumulation and subsequent oxidation of low density lipoprotein (LDL). The endothelial dysfunction is followed by adhesion and migration of monocytes and T cells to the intima in response to the surface expression of endothelial adhesion molecules such as selectins, VCAM-1, ICAM-1 and chemotactic signals (MCP-1). Recruited monocytes proliferate in the intima, and differentiate into macrophages that phagocyte infiltration and oxidized lipoproteins transforming them into foam cells that characterize striae lipid (fatty streaks). The secretion of cytokines and growth factors, mainly derived from macrophages, induces migration of smooth muscle cells from the media to the intima, where they proliferate, differentiate in "synthetic" phenotype and synthesize extracellular matrix, resulting in the transformation of lipid streaks in advanced lesions: fibrous plaques 
consisting of a fibrous cap that encloses a lipid core. The accumulation of LDLs is not only due to increased permeability of functionally damaged endothelium, but also its ability to bind the extracellular matrix constituents in the intima. The LDLs undergo oxidation and plays a key role in the development of the intima chronic inflammatory reaction. The LDLs are then trapped in the extracellular matrix of the subendothelial space. Oxidation of LDLs is due to enzymes and oxidative metabolites produced by the arterial wall cells, especially by monocytes-macrophages recruited in the intima as an endothelial damage result due to various causes. Initially, LDLs lipids peroxidation takes place, which interferes poorly with the binding between LDLs and the receptor ApoB-E (or LDL-R); MM-LDLs (minimally oxidized LDLs) are "Trojan horses", physically similar to LDLs, but with a bioactive macromolecular cargo, which is introduced into the cell by endocytosis of MM-LDLs. At later stages, lipid peroxides and aldehydic products are generated (malondialdehyde, MDA, 4-hydroxynonenal) that can covalently modify the LDL protein component; these OXLDLs called "cellular saboteurs" are no longer recognized by LDL-R but bind to "scavenger receptors" (SR: SR-A, CD36 and CD68). Since SR are not subject to negative-feedback regulation, the OX-LDLs not only introduce active macromolecules into cells, but it also causes the accumulation of intracellular cholesterol esters, responsible for the transformation of macrophages into foam cells characteristic of atherosclerotic tissue.

The OX-LDLs activate some transcription factors (e.g. NF-kB) in the cells (endothelium, macrophages, smooth muscle cells), which induce the expression of genes encoding adhesion molecules, cytokines, and growth factors and triggering the inflammatory response. Experimental studies have attested that oxidized LDLs have many biological activities on arterial wall cells, including cytotoxic action and direct mitogenic action on smooth muscle cells, macrophages, fibroblasts and endothelial cells. In the endothelium they induce the expression of adhesive molecules on leukocytes, stimulate the production of chemotactic substances (which are partly related to the endothelial surface and are partly released in subendotelium) and promote the synthesis of growth factors for monocytes/macrophages and smooth muscle cells, stimulate the synthesis of PAI-1 (plasminogen activator inhibitor-1) and tissue factor promoting coagulation, stimulate the production of endothelium and inhibit NO, inhibiting endothelium-dependent vasodilation. These species have a direct chemotactic effect on macrophages; determine the transformation into foam cells, stimulate the production of cytokines, growth factors and metalloproteases. In smooth muscle cells induce the synthesis of MCP-1. Finally, oxidized LDL activates platelets and cause aggregation. The fibrous plaques may experience more complications (ulceration, bleeding, thrombosis, calcification) determining the third and most serious atherosclerotic stage: the complicated lesions. There are many factors responsible for plaque fissuring, in particular the great importance of plaque inflammation and abundant lipid component that would make the plate less resistant to the blood component. Inflammatory cells and especially macrophages produce hydrolytic enzymes such as metalloproteases able to lyse the collagen of the fibrous cap that becomes less resistant to hemodynamic stress.

Moreover, elevated levels of some inflammatory markers predict the outcome of patients with acute coronary syndrome regardless of myocardial damage. The reactive $\mathrm{C}$ protein adds to the most common risk factors such as negative prognostic index for atherosclerotic cardiovascular events even in apparently healthy subjects as shown by Ridker. It is now commonly accepted that the cardiovascular risk increases for PCR levels in serum above $5 \mathrm{mg} / \mathrm{l}$, but some authors have shown that subjects with PCR levels greater than 3.6 have a risk for cardiovascular events 2 times higher than the rest of general population.

\section{Alzheimer's disease}

Alzheimer's disease is the most common neurodegenerative disease in Western Europe and an important public health problem as the number of cases is increasing with the aging of the population. It manifests with progressive decline in memory and intellectual abilities, impoverishment of language, disorientation and behavioral skills. The characteristic neuropathological aspects of Alzheimer's disease (AD) are senile plaques (SP), neuro fibrillar clusters (NFT) and amyloid angiopathy. The NFT are accumulations of dystrophic neurites containing double helix filaments whose main component is the phosphorylated form of tau protein encoded by chromosome 17 and associated with microtubules. Amyloid beta deposits are observed both within the cerebral vessel wall and, more typically, as SP represented by a central core of beta amyloid fibrils surrounded by a ring of dystrophic neurites, reactive astrocytes and microglia. The beta amyloid protein originates from the cleavage of a precursor consisting in two fragments of 40 (Abeta1-40) and 42 amino acids (Abeta1-42). About $\mathrm{AD}$ it is known a familial form (FAD) with autosomal dominant. In more than $50 \%$ of cases of this type have been identified mutations in the amyloid precursor protein (APP) on chromosome 21 [98], presenilin 1 gene (PS-1) on chromosome 14 [99] and presenilin 2 gene (PS-2) on chromosome 1 [100]. These changes are associated with increased production of amyloid beta fragment 1-42 (Abeta), highly toxic for neurons and main component of the plaques observed in $\mathrm{AD}$. However, the role of genetic factors in the sporadic $\mathrm{AD}$ pathogenesis is not completely clear and is likely involved multiple risk factors. The presence of epsilon 4 allele (e4) in the gene for apolipoprotein $\mathrm{E}$ (APOE) is the major genetic risk factor associated to the development of sporadic AD. Subjects carrying respect to non-carrying e4 allele has a developing $\mathrm{AD}$ risk by three (in heterozygote's) to eight (in homozygote's) times greater. The e4 promotes the deposition of Abeta in extraneuronal plaques. The annual incidence rate is estimated about $1 \%$ in subjects over 65 years old to more than $3 \%$ in patients over eighty. Immune responsiveness in AD appears to be altered [101,102]. In the brain of these patients there are some acute phase proteins and elements of the immune system, although there are the classic inflammation signs such as oedema and neutrophil invasion. Alterations of this type found in the brains of patients affected by $\mathrm{AD}$, but not in agematched healthy controls, include a greater number of receptors for immunoglobulin and for the complement, increased microglial expression of major histocompatibility complex, increased production of cytokines (like IL-1beta, IL-6), increased acute phase proteins alpha1-antichymotrypsin (ACT) and infiltration of T lymphocytes in the tissues [103-106]. A case-control study (103) showed that plasma levels of ACT are related to the degree of cognitive impairment in $\mathrm{AD}$ patients and that peripheral markers of inflammation or altered immune response could be used to monitor disease progression. The role of inflammation is further underlined by epidemiological studies showing that the long-term use of NSAIDs may protect against AD [107]. From the immunohistochemical prospective microglia is phenotypically related to monocytes, which replaces in phagocytic role in brain. It also expresses a number of important marker of immune function including major histocompatibility antigens type I and II, which facilitates interaction with T lymphocytes. It is shown by numerous studies the increased concentrations of some cytokines and their receptors that regulate and amplify immune responses, conversely lymphocytic infiltration does not seem to be an important 
component. Complement system also participate to these reactive processes [108]. When complement system is activated prepares the cell to the phagocytosis and stimulates the cytolysis. Antibodies against complement components are demonstrated in brain tissue of patients with AD but they don't bind to age-matched controls tissues. These and other data imply that in this disease there is activation of the complement reactions cascade to the production of a lytic membrane complex; neurons exposed to the complex are defended increasing the synthesis of inhibitors. However, in the disease status prevails the process of selfdestruction and phagocytosis. These findings provide helpful tips for $\mathrm{AD}$ treating, such as assumptions regarding the use of inflammatory, and stimulate suggestive questions such as what is the relationship between beta-amyloid and inflammatory response. It seems that Betaamyloid directly activate components of the inflammatory response as the complement cascade and microglia [109] and macrophages activity. The 1-40 and 1-42 forms of the peptide evoke neurotoxins release by microglia, including a newly-identified [105], and it seems also involved a "scavenger receptor" present on microglia that should bind beta-amyloid. According to some authors, the beta-amyloid may activate the cytotoxic response of mononuclear phagocytes and macrophages, causing a cytopathic response directed against neuronal elements. In terms of measurable parameters directly in the patient were observed high antibodies values against microglia in liquor, indirect evidence of abnormal activation system. Despite the progress made by research in this area and even though it was discovered the direct confirmation that brain tissue inflammatory cascade involving COX-2 is activated in patients with this disease [110-112], clinical data, as opposed to the epidemiologicals, are disappointing [113]. The only recent trial using prednisone gave essentially negative results [114]. In conclusion, the brainlesions associated with $\mathrm{AD}$ such as neurofibrillary tangles and senile plaques, are characterized by the presence of a broad spectrum of inflammatory mediators produced by cells residing in the brain, including neurons. Although of secondary importance compared to the fundamental cause that determines the tangles and plaques, there are strong evidences that inflammation exacerbates the neuronal loss. Consequently, the $\mathrm{AD}$ risk is substantially influenced by several polymorphisms in the promoter region of genes, and other non-coding regions, coding for inflammatory mediators. Alleles that support the increased expression of inflammatory mediators or alleles that favour the reduced expression of anti-inflammatory mediators are more frequent in patients with $\mathrm{AD}$ compared to controls. The polymorphisms are fairly common in the general population, so there is a strong probability that everyone will inherit one or more high risk alleles [104,115-123].

\section{Benefical effects of mediterranean diet in neuroinflam- mation and related diseases}

Despite during recent years many theories about aging have been developed we are still far from a full explanation of the mechanisms underlying the aging process. It has not yet been found an answer to the question that always arises from the man: "why grow old? "," what do to live longer?". Great strides have been made by immunologicalinflammatory research, but it is still waiting for effective and validated therapeutic strategies. It has great consensus the hypothesis that aging is multifactorial and complex process, produced by the interaction between genetic, environmental and lifestyle. According to the latest scientific understanding our genes are programmed to make us live 120 years. But we know that longevity is not only written in the genes, but for a good $70 \%$ must conquer day by day with healthy lifestyles. So from the earliest years of life is essential for healthy nutrition, physical exercise constant, constant mental activity, a limited use of tobacco and alcohol, a life away from polluted environments, with limited sun exposure and most importantly it is necessary to lead a life animated by many interests [124-138].

Epidemiological studies have shown an inverse association between adherence to the mediterranean diet and the risk of chronic and neurodegenerative diseases, the most frequent causes of mortality in industrialized countries. Greater adherence to the Mediterranean diet is associated with a reduction in the incidence of cardiovascular mortality (10\%) and a reduction of all-cause mortality (8\%) [124-138].

The paternity of research on the Mediterranean Diet is to be attributed to the nutritionist Lorenzo Piroddi (1911 - 1999), who in 1939 hypothesized the connection between eating habits and the onset of the diseases of the exchange. To cure his patients, Piroddi developed a first version of the Mediterranean Diet, which limited the consumption of animal fats favoring the vegetable ones.

But the first scholar who brought the concept of "Mediterranean Diet" to the attention of science was Ancel Keys (1904 - 2004) [124-138].

The indicators of adequacy to the most used Mediterranean Diet are:

1) Mediterranean Adequacy Index (MAI), created by AlbertFidanza, is built on the Mediterranean Diet of reference, ie that taken in 1960 in Nicotera (which was then designated in the Seven Countries Study as the third Italian rural area), dividing the percentage of energy deriving from the consumption of typical Mediterranean foods for that deriving from foods of a typically non-Mediterranean diet. The MAI of the men of Nicotera of 40-50 years amounted to 7.5. Analyzing the MAI it was possible to see how the diet of population groups examined in Italy in the last four decades has changed, progressively abandoning the nutritional characteristics of the ItalianMediterranean diet. Even the diet of the subjects of Nicotera, has undergone profound changes in quality over time, in fact after 42 years the MAI has fallen to 3.5 for men [124-138].

2) The Mediterranean Diet Score (MDS), created by Antonia Trichopoulou, is a scale that indicates the degree of adhesion through 9 components and determines a score from 0 to 9 (from the minimum grade to the maximum degree of adherence to the Mediterranean diet [124-138].

3) The Mediterranean Diet Score, created by Panagiotakos, evaluates the consumption of 11 categories of food products with a score from 0 to 5 depending on the portions taken weekly [124-138].

\section{The mediterranean diet foods}

The undisputed protagonists of the Mediterranean diet are: olive oil, whole grains, fresh fruit, vegetables, fish, legumes, a moderate number of dairy products and meat, red wine [124-138].

\section{Olive oil}

It is the heart of the Mediterranean diet, and determines its taste. It is the most used fat, and this is good: it is rich in monounsaturated fatty acids and in particular of oleic acid (70-86\%), thanks to this particular feature is one of the best condiments to keep under control the serum concentrations of lipoproteins very low density rich in LDL cholesterol which tends to remain in the blood and to settle on the walls of the arteries. Furthermore, the relatively high concentration of oleic acid in the membrane phospholipids, makes the cell less susceptible to oxidation, reducing the formation of pro-inflammatory molecules [124-138]. 
It is rich in polyphenols, substances that in addition to having antioxidant characteristics, stimulate the expression of genes that protect us from cancer. Some of these compounds, in particular flavonoids and secoiridoids, have shown significant effects in the prevention of chronic diseases such as cardiovascular diseases, some types of tumors, premature aging and degenerative diseases of the nervous system, so they could help to explain the health effects of extra virgin olive oil in addition to the oleic acid content [124-138].

Olive oil is not only important for its intrinsic properties, but also because it replaces other fats widely used in non-Mediterranean kitchens, such as those of animal origin (lard or butter) or from lower quality vegetable oils. Let's not forget, however, that it is still a fat and that all fats, regardless of other nutritional characteristics, have the same caloric intake [124-138].

\section{Whole grains}

They are representative of the Mediterranean Diet, in fact they occupy the base of the food pyramid with vegetables and fruit. Cereals are a group of foods that include corn, barley, rice, wheat (soft and hard wheat) and spelled. They are an important source of nutritive energy and provide this energy in the form of starch, polysaccharide from which glucose is obtained after the digestive process, and are also a good source of protein. Whole grains are those that keep intact bran and germ and are rich in iron, B vitamins and fibers that facilitate intestinal transit and limit the contact of some harmful elements with the gastrointestinal mucosa. Many cereals can be ground to make different types of flour, which may have retained the original composition for the entire production path or have been reconstituted. These flours are then used for the production of pasta, bread and other baked goods [124-138].

Current epidemiological evidence indicates that whole grains have a beneficial effect on health. Whole grain foods substantially reduce the risk of cardiovascular disease, diabetes and cancer and also play a part in body weight management and digestive health. Essential macro and micronutrients with phytonutrients present in whole grains contribute synergistically to their beneficial effects. The inverse association between whole grain intake and cardiovascular disease was demonstrated by a meta-analysis that evaluated seven cohort studies highlighting that the increased total grains intake ( 2.5 portions compared to 0.2 per day) was associated with a $21 \%$ lower risk of cardiovascular events. On the contrary, there was no correlation with the intake of refined cereals, in which the relative concentration of starch is higher because most of the bran and some parts of the germ are removed in the refining process [124-138].

A recent intervention trial showed a greater reduction of fat mass without any change in body weight, in the group that took whole grains compared to that with refined grains. Also for the risk of type 2 diabetes mellitus has been demonstrated an inverse association with the intake of whole grains; the beneficial effects may be due to the structure of whole grains and nutrients present in whole grains, such as magnesium and antioxidants such as vitamin E, phytic acid and selenium [124-138].

A recent meta-analysis of 25 prospective observational studies confirmed the reduction in colorectal cancer risk, resulting in an increase of 3 portions per day of whole grains. The nutritional components of whole grains, which exert their action in improving health by preventing chronic-degenerative diseases, include tocotrienols, lignans and phenolic compounds, and anti-nutrients such as phytic acid, tannins and enzymatic inhibitors [124-138].

\section{Fresh fruit and vegetables}

They are foods with reduced caloric power, rich in fiber, water, vitamins and minerals. The dietary fiber present in fruits and vegetables increases the distension of the stomach with an increase in the sense of satiety which consequently leads to not exceeding the consumption of other types of foods with higher caloric power. The portions of fruit and vegetables consumed per day must be five. Always choosing seasonal fruit and vegetables limits the risk of using harmful substances used in agriculture with them, helps to preserve biodiversity and also the organoleptic qualities are superior [124-138].

\section{Fish}

It is a food that has shaped and determined the history of the countries bordering the Mediterranean. It is an excellent source of protein, vitamin $\mathrm{D}$, of omega-3 long-chain polyunsaturated fatty acids and some mineral salts such as selenium, phosphorus and potassium that regulate the exchange of substances through the cell membrane and therefore affect the normal functioning of all the cells of our body. Particular attention is given to the presence of omega- 3 fatty acids, which include eicosapentenoic acid and docosahexaenoic acid, defined as essential because our body is not able to produce them, and must therefore necessarily be taken with the diet. Consumption of omega-3 protects the cardiovascular system, decreasing the risk of coronary heart disease, hypertension, atherosclerosis, thrombosis [124-138].

They have antithrombotic effects as they inhibit the platelet aggregation, substituting arachidonic acid to produce the thromboxane A3 without any aggregating and weak vasoconstrictor effects and antidyslipidemic effects, as they reduce the expression of ApoB100 of LDL [124-138].

\section{Legumes}

Often called the "meat of the poor", they have a dual function, both for the presence of slow-absorbed carbohydrates and for the good protein content they possess. The association of cereals and legumes is complete from the protein point of view, as it provides the body with all the essential amino acids we need. Legumes have a fair amount of mineral salts, some vitamins and dietary fiber, which helps to reach a sense of satiety. They also help to modulate the glycemic response of the meal [124-138].

\section{Dairy products and meat}

As for meat, we tend to prefer white to red. It is rich in proteins, fats whose quota depends on the type of breeding and origin of the animal, vitamins and mineral salts. Milk is an excellent source of protein, minerals and vitamins [124-138].

\section{Wine}

Attention goes to the presence of antioxidants such as resveratrol and quercetin. These substances are important because they have the power to protect the proteins, lipids and nucleic acids of the cells from the attack of free radicals. Obviously, it is not possible to pursue an anti-radical or completely protective objective, because it would coincide with an excessive amount of alcohol. The concept therefore remains that a good glass of red wine can help to exercise positive actions not only for the reduction of cardiovascular risks, but also for the improvement of the lipid pattern, of the hemostatic balance, of blood pressure, of insulin sensitivity, of cholesterol level. HDL [124-138].

Each food, therefore, has beneficial effects on health, when the consumption of these is adequate and proportionate in the right 
amounts, to meet the energy and nutrient needs of the body. It is essential to stress that all the meals of a day, starting from breakfast, lunch, dinner and snacks, must be balanced, that is to contain all the nutrients we need, a goal that can be reached easily with a diet as varied as possible as the Mediterranean diet indicates to us [124-138].

Always pay attention to the quantity, but above all to the balance of the nutrients that bring energy, respecting in particular the following proportions: $55-60 \%$ of the energy from the carbohydrates, $12-15 \%$ from the proteins, $25-30 \%$ from the fats. We can also say with certainty that the Mediterranean diet can be a useful tool for reducing body weight, with moderate caloric restriction associated with physical activity [124-138].

\section{Conclusions}

While nutritional strategies that reduce inflammation and oxidative stress appear to hold promise for preventing neurodegenerative disease, it's important to note that some nutritional factors may actually enhance brain inflammation. Obesity seems to be on the top of the list of concerns. Studies have shown that people with higher levels of adiposity are at higher risk for both future PD and $\mathrm{AD}$ and that central adiposity is related to cognitive decline and dementia. Body fat promotes inflammation. Body fat may store toxins. A fatter person even has a smaller hippocampus, says Perlmutter of links between obesity and neurodegeneration. Diabetes is linked with a higher risk of dementia and $\mathrm{AD}$ as well. Brain inflammation may also be bolstered by advanced glycosylation end products (AGEs), molecules formed during a nonenzymatic reaction between proteins and sugar residues called the Maillard reaction. AGEs produce a "fifty-fold increase in free radicals and increase the risk of AD by $400 \%$," according to Perlmutter. AGEs can create adverse effects on tissues and cells, including the activation of intracellular signal transduction pathways leading to the upregulation of cytokine and free radical production [124-138].

It may seem strange, but the much-publicized Mediterranean Diet, which we should all follow to be better and prevent diseases of wellbeing and which represented the basis of eating habits until the middle of the twentieth century in all the countries of the area, is progressively disappearing from the Mediterranean countries, from Italy, from Greece, from Spain and also from the Middle East and from North Africa, because of the wide diffusion of the western economy, of the urban and technological culture and of the globalization of production and consumption. The food choices are oriented towards what the market offers, depending on the efficiency and speed of transport, distribution networks and the effectiveness of conservation technologies and become increasingly disconnected from seasonality and tradition [124-138]. In the last years, the Mediterranean style has undergone a profound change: the diet has progressively been enriched with foods high in protein, saturated fats and simple sugars because they have become more frequent both meals outside the home (for necessity and for laziness) that the consumption of ready-made foods (very different qualitatively from those consumed in the 60s) and also the portions of Italians have increased by $30-40 \%$ (from 2,500 to $3,300 \mathrm{kcal} /$ day), with a progressive impoverishment of plant origin and complex carbohydrates. This increase in the calorie intake did not follow an adequate energy expenditure because the lifestyle has become more sedentary as it is linked to transport and work more and more to the machines, thus resulting in a significant reduction in daily energy expenditure [124-138]. We live, therefore, in an era of "apparent well-being", where the growth of overweight and obesity and of all the related pathologies is also registered when life expectancy is prolonged. The Mediterranean food model should not be abandoned, but rediscovered, re-evaluated and proposed daily in the tables of all the people [124-138]. The smart lesson to be learned about health and function? Don't neglect mediterranean diet.

\section{References}

1. Wachter KW, Finch CE (1997) Between Zeus and the Salmon. Washington: National Academ Press.

2. Weinert BT, Timiras PS (2003) Theories of aging. J Appl Physiol 95: 1706-16.

3. Kowald A, Kirkwood TB (1996) A network theory of ageing: the interactions of defective mitochondria, aberrant proteins, free radicals and scavengers in the ageing process. Mutat Rs 316: 209-236.

4. Migliaccio E, Giorgio M, Mele S, Pelicci G, Reboldi P, et al. (1999) The p66shc adaptor protein controls oxidative stress response and life span in mammals. Nature 402: $309-313$

5. Puca AA, Daly MJ, Brewster SJ, Matite TC, Barrett J, et al. (2001) A genome-wide scan for linkage to human exceptional longevity identifies a locus on chromosome 4. Proc Natl Acad Sci USA 98: 10505-105-8.

6. Hayflick L (1965) The limited in vitro lifetime of human diploid cell strains. Exp Cell Res 37: 614-636.

7. Campisi J (2003) Cellular Senescence and Cell Death. In: Timiras PS. Third ed. Physiological Basis of Aging and Geriatrics. Boca Raton: CRC Press, pp: 47-59.

8. Blackburn EH (2000) Telomere states and cell fates. Nature 408: 53-56

9. Kim NW, Piatyszek MA, Prowse KR, Harley CB, West MD, et al. (1994) Specific association of human telomerase activity with immortal cells and cancer. Scie 266 2011-2015

10. Reddel RR (2000) The role of senescence and immortalization in carcinogenesis. Carcinogenesis 21: 477-484. [Crossref]

11. Ferrara N, Gorbi G, Scarpa D, Rengo G, Longobardi G (2005) Teorie dell'invecchiamento. The aging theories. G Gerontol 53: 57-74.

12. Smith RG, Betancourt L, Sun Y (2005) Molecular endocrinology and physiology of the aging central nervous system. Endocr Rev 26: 203-250. [Crossref]

13. Grémiaux A, Yokawa K, Mancuso S, Baluška F (2014) Plant anesthesia supports similarities between animals and plants: Claude Bernard's forgotten studies. Plant Signal Behav 9: e27886. [Crossref]

14. Cannon WB (1932) The Wisdom of the Body. New York: WW Norton \& Co.

15. McEwen BS (2002) The End of Stress as We Know It. Washington: Joseph Henry Press.

16. Hutchinson J (1986) Association between stress and blood pressure variation in a Caribbean population. Am J Phys Anthropol 71: 69-79. [Crossref]

17. Nawata H, Yanase T, Goto K, Okabe T, Nomura M, et al. (2004) Adrenopause. Horm Res 62 Suppl 3: 110-114. [Crossref]

18. Graham D, McLachlan A (2004) Declining melatonin levels and older people. How old is old? Neuro Endocrinol Lett 25: 415-418. [Crossref]

19. Arendt J (1988) Melatonin. Clin Endocrinol (Oxf) 29: 205-229. [Crossref]

20. Armstrong SM, Redman JR (1991) Melatonin: a chronobiotic with anti-aging properties? Med Hypotheses 34: 300-309. [Crossref]

21. Bondy SC, Sharman EH (2007) Melatonin and the aging brain. Neurochem Int 50 571-580. [Crossref]

22. Pierpaoli W, Regelson W (1994) Pineal control of aging: effect of melatonin and pineal grafting on aging mice. Proc Natl Acad Sci U S A 91: 787-791. [Crossref]

23. Karasek M (2004) Melatonin, human aging, and age-related diseases. Exp Gerontol 39: 1723-1729. [Crossref]

24. Rudman D, Feller AG, Nagraj HS, Gergans GA, Lalitha PY, et al. (1990) Effects of human growth hormone in men over 60 years old. $N$ Engl J Med 323: 1-6. [Crossref]

25. Nass R, Park J, Thorner MO (2007) Growth hormone supplementation in the elderly. Endocrinol Metab Clin N Am 2007: 3633-3645.

26. Snyder PJ, Peachey H, Hannoush P, Berlin JA, Loh L, et al. (1999) Effect of testosterone treatment on body composition and muscle strength in men over 65 years of age. $J$ Clin Endocrinol Metab 84: 2647-2653. 
27. Stoll BA (1999) Dietary supplements of dehydroepiandrosterone in relation to breast cancer risk. Eur J Clin Nutr 53: 771-775. [Crossref]

28. Effros RB (2004) From Hayflick to Walford: the role of T cell replicative senescence in human aging. Exp Gerontol 39: 885-890. [Crossref]

29. Gerli R, Paganelli R, Cossarizza A, Muscat C, Piccolo G, et al. (1999) Long immunologic effects in thymectomy in patients with myasthenia gravis. Clin Immunol 103: 865-72.

30. Effros RB (2001) Ageing and the immune system. Novartis Found Symp 235: 130-139. [Crossref]

31. Fagnoni FF, Vescovini R, Mazzola M, Bologna G, Nigro E, et al. (1996) Expansion of cytotoxic CD8+ CD28- T cells in healthy ageing people, including centenarians. Immunology 88: 501-507. [Crossref]

32. Timm JA, Thoman ML (1999) Maturation of CD4+ lymphocytes in the aged microenvironment results in a memory-enriched population. J Immunol 162: 711-717. [Crossref]

33. Effros RB (2000) Long-term immunological memory against viruses. Mech Ageing Dev 121: 161-171. [Crossref]

34. Wikby A, Johansson B, Olsson J, Lofgren S, Nilsson BO, et al. (2002) Expansions of peripheral blood CD8 T-lymphocyte subpopulations and an association with citomegalovirus seropositivity in the elderly: the Swedish NONA immunestudy. Exp Gerontol 37: 45-53.

35. Pawelec G, Ouyang Q, Wikby A (2003) Pathways to a robust immuneresponse in the elderly. Immunology and Allergy Clinics of North America: Impact of Immune Senescence on Human Aging. Philadelphia: WB Saunders Co.

36. Bonaf M, Valensin S, Gianni W, Marigliano V, Franceschi C (2001) The unexpected contribution of immunosenescence to the levelling off of cancer incidence and mortality in the oldest old. Critical Reviews in Oncology/Hematology 39: 227-33.

37. Pahlavani MA (1998) T cell signaling: effect of age. Front Biosci 3: D1120-1133. [Crossref]

38. Franceschi C1, Monti D, Sansoni P, Cossarizza A (1995) The immunology of exceptional individuals: the lesson of centenarians. Immunol Today 16: 12-16. [Crossref]

39. Sansoni P, Cossarizza A, Brianti V, Fagnoni F, Snelli G, et al. (1993) Lymphocyte subsets and natural killer cell activity in healthy old people and centenarians. Blood 82 : 2767-2773. [Crossref]

40. Franceschi C, Monti D, Barbieri D, Grassilli E, Troiano L, et al. (1995) Immunosenescence in humans: deterioration or remodelling? Int Rev Immunol 12: 5774. [Crossref]

41. Ogata K, Yokose N, Tamura H, An E, Nakamura K (1997) Natural killer cells in the late decades of human life. Clin Immunol Immunopathol 84: 269-75.

42. Remarque E, Pawelec P (1998) T cell immunosenescence and its clinical relevance in man. Rev Clin Gerontology 8: 5-14.

43. Kourilsky P, Truffa-Bachi P (2001) Cytokine fields and the polarization of the immune response. Trends Immunol 22: 502-509. [Crossref]

44. Forsey RJ, Thompson JM, Ernerudh J, Hurst TL, Strindhall J, et al. (2003) Plasma cytokine profiles in elderly humans. Mech Ageing Dev 124: 487-493. [Crossref]

45. Franceschi C, Bonafè M, Valensin S, Olivieri F, De Luca M, et al. (2000) Inflammaging. An evolutionary perspective on immunosenescence. Ann N Y Acad Sci 908: 244254. [Crossref]

46. Kerr JF, Wyllie AH, Currie AR (1972) Apoptosis: a basic biological phenomenon with wide-ranging implications in tissue kinetics. Br J Cancer 26: 239-257.

47. Akbar AN, Salmon M (1997) Cellular environments and apoptosis: tissue microenvironments control activated T-cell death. Immunol Today 18: 72-76. [Crossref]

48. Krammer PH (2000) CD95's deadly mission in the immune system. Nature 407: 789795. [Crossref]

49. Gupta S (2001) Molecular steps of death receptor and mitochondrial pathways of apoptosis. Life Sci 69: 2957-2964. [Crossref]

50. Hengartner MO (2000) The biochemistry of apoptosis. Nature 407: 770-776. [Crossref]

51. Jäättelä M, Tschopp J (2003) Caspase-independent cell death in T lymphocytes. Nat Immunol 4: 416-423. [Crossref]

52. Franceschi C, Valensin S, Bonafè M, Paolisso G, Yashin AI, et al. (2000) The network and the remodeling theories of aging: historical background and new perspectives. Exp Gerontol 35: 879-896. [Crossref]
53. De Martinis M, Franceschi C, Monti D, Ginaldi L (2007) Apoptosis remodeling in immunosenescence: implications for strategies to delay ageing. Curr Med Chem 14 1389-1397. [Crossref]

54. Franceschi C, BonafÃ M, Valensin S (2000) Human immunosenescence: the prevailing of innate immunity, the failing of clonotypic immunity, and the filling of immunological space. Vaccine 18: 1717-1720.

55. Finkel T, Holbrook NJ (2000) Oxidants, oxidative stress and the biology of ageing. Nature 408: 239-247. [Crossref]

56. Franceschi C (1989) Cell proliferation and cell death in the aging process. Aging Clin Exp Res1: 3-1.

57. Franceschi C, Ottaviani E (1997) Stress, inflammation and natural immunity in the aging process: a new theory. Aging (Milano) 9: 30-31. [Crossref]

58. Salvioli S, Capri M, Valensin S, Tieri P, Monti D, et al. (2006) Inflamm-Aging, Cytokines and Aging: State of the Art, New Hypotheses on the Role of Mitochondria and New Perspectives from Systems Biology. Current Pharmaceutical Design 12: 3161-3171.

59. De Martinis M, Franceschi C, Monti D, Ginaldi L (2005) Inflamm-ageing and lifelong antigenic load as major determinants of ageing rate and longevity. FEBS Lett 579: 2035-2039. [Crossref]

60. Fagiola U, Cossarizza A, Scala E, Fanales-Belasio E, Ortolani C, et al. (1993) Increased cytokine production in mononuclear cells o healthy elderly people. Eur J Immunol 23 : 2375-237.

61. Franceschi C, Monti D, Sansoni P, Cossarizza A (1995) The immunology of exceptional individuals: the lesson of centenarians. Immunol Today 16: 12-16. [Crossref]

62. Lio D, Scola L, Crivello A, Colonna-Romano G, Candore G, et al. (2003) Inflammation, genetics, and longevity: further studies on the protective effects in men of IL-10 -1082 promoter SNP and its interaction with TNF- -308 promoter SNP. J Med Genet 40 296-299.

63. Candore G, Colonna-Romano G, Balistreri CR, Di Carlo D, Grimaldi MP, et al. (2006) Biology of longevity: role of the innate immune system. Rejuvenation Res 9: 143-148. [Crossref]

64. Giunta S (2006) Is inflammaging an auto[innate]immunity subclinical syndrome? Immun Ageing 3: 12. [Crossref]

65. Franceschi C, Motta L, Valensin S, Rapisarda R, Franzone A (2000) Do men and women follow different trajectories to reach extreme longevity. Aging Clin Exp Res 12: 77-84.

66. Ginaldi L, De Martinis M, Monti D, Franceschi C (2004) The immune system in the elderly: activation-induced and damage-induced apoptosis. Immunol Res 30: 81-94. [Crossref]

67. Bonaf M, Olivieri F, Cavallone L, Giovagnetti S, Mayegiani F, et al. (2001) A gender-dependent genetic predisposition to produce high levels of IL-6 is detrimental for longevity. Eur J Immunol 31: 2357-2361. [Crossref]

68. Salvioli S, Capri M, Valensin S, Tieri P, Monti D, et al. (2006) Inflamm-aging, cytokines and aging: state of the art, new hypotheses on the role of mitochondria and new perspectives from systems biology. Curr Pharm Des 12: 3161-3171. [Crossref]

69. Capri M, Salvioli S, Sevini F, Valensin S, Celani L, et al. (2006) The genetics of human longevity. Ann N Y Acad Sci 1067: 252-263. [Crossref]

70. Franceschi C, Bezrukov V, Blanché H, Bolund L, Christensen K, et al. (2007) Genetics of healthy aging in Europe: the EU-integrated project GEHA (GEnetics of Healthy Aging). Ann NY Acad Sci 1100: 21-45.

71. Khan N, Shariff N, Cobbold M, Bruton R, Ainsworth JA, et al. (2002) Cytomegalovirus seropositivity drives the $\mathrm{CD} 8 \mathrm{~T}$ cell repertoire toward greater clonality in healthy elderly individuals. J Immunol 169: 1984-1992.

72. Ouyang Q, Wagner WM, Walter S, Muller CA, Wikby A, et al. (2003) The age-related increase in CD8+ T cells carrying receptors for an immunodominant Epstein-Barr virus (EBV) epitope is counterbalanced by decreased antigen-specific responsiveness. Mech Ageing Dev 124: 477-485.

73. Pawelec G, Akbar A, Caruso C, Solana R, Grubeck-Loebenstein B, et al. (2005) Human immunosenescence: is it infectious? Immunol Rev 205: 257-268. [Crossref]

74. Vescovini R, Telera A, Fagnoni FF, Biasini C, Medici MC, et al. (2004) Different contribution of EBV and CMV infections in very long-term carriers to age-related alterations of CD8+ T cells. Exp Gerontol 39: 1233-1243. [Crossref]

75. Bürkle A, Caselli G, Franceschi C, Mariani E, Sansoni P, et al. (2007) Pathophysiology of ageing, longevity and age related diseases. Immunity \& Ageing 4: 4 
76. Kammerman EM, Neumann DM, Ball MJ, Lukiw W, Hill JM (2006) Senile plaques in Alzheimer's diseased brains: possible association of beta-amyloid with herpes simplex virus type 1 (HSV-1) L-particles. Med Hypotheses 66: 294-299.

77. Itzhaki R (2004) Herpes simplex virus type 1, apolipoprotein E and Alzheimer' disease. Herpes 11 Suppl 2: 77A-82A. [Crossref]

78. Letenneur L, Peres K, Fleury H, Garrigue I, Barberger-Gateau P, et al. (2008) Seropositivity to herpes simplex virus antibodies and risk of Alzheimer's disease: a population-based cohort study. PLOS ONE 3: 36-37.

79. Ginaldi L, De Martinis M, Monti D, Franceschi C (2004) The immune system in the elderly: activation-induced and damage-induced apoptosis. Immunol Res 30: 81-94.

80. Cesari M, Penninx BW, Pahor M, Lauretani F, Corsi AM, et al. (2004) Inflammatory markers and physical performance in older persons: the InCHIANTI study. J Gerontol A Biol Sci Med Sci 59: 242-248. [Crossref]

81. Rowshani AT, Bemelman FJ, van Leeuwen EM, van Lier RA, ten Berge IJ (2005) Clinical and immunologic aspects of cytomegalovirus infection in solid organ transplant recipients. Transplantation 79: 381-386.

82. Salvioli S, Olivieri F, Marchegiani F, Cardelli M, Santoro A, et al. (2006) Genes, ageing and longevity in humans: problems, advantages and perspectives. Free Radic Res 40: 1303-1323. [Crossref]

83. Carrieri G, Marzi E, Olivieri F, Marchegiani F, Cavallone L, et al. (2004) The G/C915 polymorphism of transforming growth factor beta1 is associated with human longevity: a study in Italian centenarians. Agin Cell 3: 443-448.

84. Caruso C, Lio D, Cavallone L, Franceschi C (2004) Aging, longevity, inflammation, and cancer. Ann N Y Acad Sci 1028: 1-13. [Crossref]

85. Franceschi C, Capri M, Monti D, Giunta S, Olivieri F, et al. (2007) Inflammaging and anti-inflammaging: a systemic perspective on aging and longevity emerged from studies in humans. Mech Ageing Dev 128: 92-105. [Crossref]

86. Pawelec G, Akbar A, Caruso C, Solana R, Grubeck-Loebenstein B, et al. (2005) Human immunosenescence: is it infectious? Immunol Rev 205: 257-268. [Crossref]

87. Gloeckler Ries LA, Reichman ME, Lewis DR, Hankey BF, Edwards BK (2003) Cancer survival and incidence from the Surveillance, Epidemiology, and End Results (SEER) program. Oncologist 8: 541-552.

88. Serrano M, Blasco MA (2007) Cancer and ageing: convergent and divergent mechanisms. Nat Rev Mol Cell Biol 8: 715-722. [Crossref]

89. Finkel T, Serrano M, Blasco MA (2007) The common biology of cancer and ageing. Nature 448: 767-774. [Crossref]

90. Derhovanessian E, Solana R, Larbi A, Pawelec G (2008) Immunity, ageing and cancer. Immun Ageing 5: 11. [Crossref]

91. Thun MJ, Henley SJ, Gansler T (2004) Inflammation and cancer: an epidemiological perspective. Novartis Found Symp 256: 6-21. [Crossref]

92. Macarthur M, Hold GL, El-Omar EM (2004) Inflammation and Cancer II. Role of chronic inflammation and cytokine gene polymorphisms in the pathogenesis of gastrointestinal malignancy. Am J Physiol Gastrointest Liver Physiol 286: G515-520. [Crossref]

93. Erlinger TP, Platz EA, Rifai N, Helzlsouer KJ (2004) C-reactive protein and the risk of incident colorectal cancer. JAMA 291: 585-590. [Crossref]

94. Hussain SP, Hofseth LJ, Harris CC (2003) Radical causes of cancer. Nat Rev Cancer 3 : 276-285. [Crossref]

95. Szlosarek PW, Balkwill FR (2003) Tumour necrosis factor alpha: a potential target for the therapy of solid tumours. Lancet Oncol 4: 565-573. [Crossref]

96. Franceschi C (2007) Un fuoco maligno. Le Scienze 2007: 82-89.

97. Ross R (1999) Atherosclerosis--an inflammatory disease. N Engl J Med 340: 115-126. [Crossref]

98. Goate A, Charter-Harlin MC, Mullan M, Brown J, Crawford F, et al. (1991) Segregation of a missense mutation in the amyloid precursor protein gene with familial Alzheimer's disease. Nature 349: 704-706.

99. Sherrington R, Rogaev EI, Liang Y, Rogava EA, Levesque G, et al. (1995) Cloning of a gene bearing missense mutations in early-onset familial Alzheimer's diseae. Nature 375: 754-760.

100. Rogaev EI, Sherrington R, Rogaeva EA, Levesque G, Ikeda M, et al. (1995) Familial Alzheimer's disease in kindreds with missense mutations in a gene on chromosome 1 related to the Alzheimer's disease type 3 gene. Nature 376: 775-778. [Crossref]
101. Solerte SB, Fioravanti M, Pascale A (1998) Increased natural killer cell cytotoxicity in Alzheimer's disease may involve protein kinase C dysregulation. Neurobiol Aging 19: 191-199.

102. Solerte SB, Fioravanti M, Vignati G (1999) Dehydroepiandrosterone sulfate enhances natural killer cell cytotoxicity in humans via locally generated immunoreactive insulin-lie growth factor I. J Clin Endocrinol Metabol 84: 3260-3267.

103. Licastro F, Pedrini S, Caputo L, Annoni G, Davis LJ, et al. (2000) Increased plasma levels of interleukin-1, interleukin-6 and alpha-1-antichymotrypsin in patients with Alzheimer's disease: peripheral inflammation or signals from the brain? $J$ Neuroimmunol 103: 97-102. [Crossref]

104. Licastro F, Pedrini S, Ferri C, Casadei V, Covoni M, et al. (2000) Gene polymorphism affecting alphal-antichymotrypsin and interleukin-1 plasma levels increases Alzheimer's disease risk. Ann Neurol 48: 388-391.

105. De Luigi A, Fragiacomo C, Lucca U, Quadri P, Tettamanti M, et al. (2001) Inflammatory markers in Alzheimer's disease and multi-infarct dementia. Mech Ageing Dev 122: 1985-1995.

106. Licastro F, Chiappelli M (2003) Brain immune responses cognitive decline and dementia: relationship with phenotype expression and genetic background. Mech Ageing Dev 124: 525-528.

107. Mukherjee P, Pasinetti GM (2000) The role of complement anaphylatoxin C5a in neurodegeneration: implications in Alzheimer's disease. J Neuroimmunology 105 : 124-130.

108. Tan J, Town T, Paris D (1999) Microglial activation resulting from CD40-CD40L interaction after beta amyloid stiulation. Science 286: 2352-2355.

109. Symposium (2000) The role of inflammation in Alzheimer's disease. Neurobiol Aging 21: S285-S286.

110. Pasinetti GM, Aisen PS (1998) Cyclooxygenase-2 expression is increased in fronta cortex of Alzheimer's disease brain. Neuroscience 87: 319-324. [Crossref]

111. Ho L, Pieroni C, Winger D, Purohit DP, Aisen PS, et al. (1999) Regional distribution of cyclooxygenase-2 in the hippocampal formation in Alzheimer's disease. $J$ Neurosci Res 57: 295-303. [Crossref]

112. Pasinetti GM1 (1998) Cyclooxygenase and inflammation in Alzheimer's disease experimental approaches and clinical interventions. J Neurosci Res 54: 1-6. [Crossref]

113. Munoz DG, Feldman H (2000) Causes of Alzheimer's disease. Can Med Assoc J 162: 65-72.

114. Aisen PS, Davis KL, Berg JD (2000) A randomized controlled trial of prednisone in Alzheimer's disease. Alzheimer's Disease Cooperative Study. Neurology 54: 588593.

115. in t' Veld BA, Ruitenberg A, Hofman A, Launer LJ, van Duijn CM, et al. (2001) Nonsteroidal antiinflammatory drugs and the risk of Alzheimer's disease. $N$ Engl J Med 345: 1515-1521. [Crossref]

116. Licastro F, Chiappelli M (2003) Brain immune responses cognitive decline and dementia: relationship with phenotype expression and genetic background. Mech Ageing Dev 124: 525-528.

117. Licastro F, Grimaldi LM, Bonafe M, Martina C, Olivieri F, et al. (2003) Interleukin-6 gene alleles affect the risk of Alzheimer's disease and levels of the cytokine in blood and brain. Neurobiol Aging 24: 921-926.

118. Candore G, Balistreri CR, Colonna-Romano G, Lio D, Caruso C (2004) Major histocompatibility complex and sporadic Alzheimer's disease: a critical reappraisal. Exp 39: 645-652.

119. Akiyama H, Barger S, Barnum S, Bradt B, Bauer J, et al. (2000) Inflammation and Alzheimer's disease. Neurobiol Aging 21: 383-421.

120. Scola L, Licastro F, Chiappelli M, Franceschi C, Grimaldi LM, et al. (2003) Allele frequencies of $+874 \mathrm{~T}->$ A single nucleotide polymorphism at the first intron of IFN-gamma gene in Alzheimer's disease patients. Aging Clin Exp Res 15: 292-295.

121. Lio D, Licastro F, Scola L, Chiappelli M, Grimaldi LM, et al. (2003) Interleukin-10 promoter polymorphism in sporadic Alzheimer's disease. Genes Immun 4: 234-238.

122. McGeer PL, McGeer EG (2001) Polymorphisms in inflammatory genes and the risk of Alzheimer disease. Arch Neurol 58: 1790-1792. [Crossref]

123. Licastro F, Candore G, Lio D, Porcellini E, Colonna-Romano G, et al. (2005) Innate immunity and inflammation in ageing: a key for understanding age-related diseases. Immun Ageing 2: 8. [Crossref] 
124. Gillette-Guyonnet S, Secher M, Vellas B (2013) Nutrition and neurodegeneration: epidemiological evidence and challenges for future research. Br J Clin Pharmacol 75: 738-755. [Crossref]

125. del Balzo V1, Diolordi L, Pinto A, Giusti AM, Vitiello V, et al. (2012) Mediterranean diet pyramids: towards the Italian model. Ann Ig 24: 443-447. [Crossref]

126. Trichopoulou A (2004) Traditional Mediterranean diet and longevity in the elderly: a review. Public Health Nutr 7: 943-947. [Crossref]

127. Vasto S, Barera A, Rizzo C, Di Carlo M, Caruso C, et al. (2014) Mediterranean diet and longevity: an example of nutraceuticals? Curr Vasc Pharmacol 12: 735-738. [Crossref]

128. Ros E, Martnez-Gonzlez MA, Estruch R, Salas-Salvad J, Fit M, et al. (2014) Mediterranean diet and cardiovascular health: Teachings of the PREDIMED study. Adv Nutr 5: 330S-6S. [Crossref]

129. Knight A, Bryan J, Wilson C, Hodgson J, Murphy K (2015) A randomised controlled intervention trial evaluating the efficacy of a Mediterranean dietary pattern on cognitive function and psychological wellbeing in healthy older adults: the MedLey study. BMC Geriatr 15: 55.

130. Trichopoulou A (2004) Traditional Mediterranean diet and longevity in the elderly: a review. Public Health Nutr 7: 943-947. [Crossref]

131. Virruso C, Accardi G, Colonna-Romano G, Candore G, Vasto S, et al. (2014) Nutraceutical properties of extra-virgin olive oil: a natural remedy for age-related disease? Rejuvenation Res 17: 217-220. [Crossref]
132. Crdeno A, Snchez-Hidalgo M, Alarcn-de-la-Lastra C (2013) An up-date of olive oil phenols in inflammation and cancer: molecular mechanisms and clinical implications. Curr Med Chem 20: 4758-4776. [Crossref]

133. Menotti A, Lanti M, Puddu PE, Kromhout D (2000) Coronary heart disease incidence in northern and southern European populations: a reanalysis of the seven countries study for a European coronary risk chart. Heart 84: 238-244.

134. Leclercq C, Arcella D, Piccinelli R, Sette S, Le Donne C, et al. (2009) The Italian National Food Consumption Survey INRAN-SCAI 2005-06: main results in terms of food consumption. Public Health Nutr 12: 2504-2532.

135. Sette S, Le Donne C, Piccinelli R, Arcella D, Turrini A, et al. (2010) The third Italian National Food Consumption Survey, INRAN-SCAI 2005-06 - Part 1: Nutrient intakes in Italy. Nutr Metab Cardiovasc Dis.

136. Sofi F, Abbate R, Gensini GF, Casini A (2010) Accruing evidence on benefits of adherence to the Mediterranean diet on health: an updated systematic review and meta-analysis. Am J Clin Nutr 92: 1189-1196.

137. Sofi F, Macchi C, Abbate R, Gensini GF, Casini A (2014) Mediterranean diet and helath status: an updated meta-analysis and a proposal for a literature-based adherence score. Public Health Nutr 17: 2769-2782.

138. Bork C, Jakobsen MU, Schmidt EB (2014) Mediterranean diet and cardiovascular disease. Ugeskr Laeger 176: V09130558. [Crossref]

Copyright: ( 2018 Milano W. This is an open-access article distributed under the terms of the Creative Commons Attribution License, which permits unrestricted use, distribution, and reproduction in any medium, provided the original author and source are credited. 